\title{
$\underline{\mathbf{P}-140}$
}

\section{Phytochemical Constituents from the Flower of Allamanda Catharica (Apocynaceae)}

\author{
Jamilul Nahry", Norizan Ahmat, Agustono Wibowo, Siti Khadijah Sulaiman, Nik Khairunnisa N. A. \\ Zawawi and L. M. Ramadhan Al Muqarrabun \\ Faculty of Applied Sciences, Universiti Teknologi MARA, 40450 Shah Alam, Selangor, Malaysia; \\ E-mail: jnahry87@gmail.com
}

Allamanda catharica L. of the family Apocynaceae is a perennial shrub and known as Yellow Bell or Golden Trumpet as well as "Bunga Loceng" in Malaysia due to big yellow funnel-shaped flowers it has. The plant extracts was reported to have medical uses and potent antibacterial activity against tested pathogenic organisms [1]. Previously, iridoids and iridoid glucosides have been reported from the roots of the plant [2]. In this study, the dried powder of flowers of A. catharica L. was extracted successively by using hexane, acetone and methanol. A combination of vacuum liquid chromatography, column chromatography, radial chromatography and preparative thin layer chromatography were used in the isolation and purification process. Three iridoid derivatives; plumieride (1), plumieride coumarate (2), and allamdin (3) were isolated from the acetone extract of the flower of $A$. catharica L. The molecular structures of the isolated compounds were established based on the spectroscopic data and comparison with published data. References: [1] Sowjanya P et. al, (2012) International Journal of Pharma World Research, Vol 3 Issue 2, [2] John J and Coppen W, (1983). Phytochemistry, Vol 22 No 1, pp $179-182$.

Keywords: Apocynaceae, Allamanda catharica, iridoids, plumieride, plumieride coumarate and allamdin. 